\title{
Relationship between frontal QRS-T duration and the severity of coronary artery disease in who were non-diabetic and had stable angina pectoris
}

\author{
Halil Akın (®, Önder Bilge1 (®) \\ Department of Cardiology, Sinop Atatürk State Hospital; Sinop-Turkey \\ ${ }^{1}$ Department of Cardiology, Diyarbakır Gazi Yaşargil Training and Research Hospital; Diyarbakır-Turkey
}

\section{ABSTRACT}

Objective: There is a known relationship between frontal-QRS-T (F-QRS-T) angle and coronary artery disease (CAD). This study examined the relationship between F-ORS-T angle changes and CAD severity in patients with stable CAD.

Methods: A total of 202 patients were included in the study after the implementation of exclusion criteria among 894 patients, who were admitted to the outpatient clinic with stable angina pectoris between September 2018 and September 2019. The F-ORS-T angle calculated on the 12-lead electrocardiograms (ECGs) of the patients (taken in the outpatient clinic), and the CAD severity calculated using the Gensini score in patients undergoing coronary angiography were compared.

Results: Of the patients included in the study, $38.6 \%$ were female and $61.4 \%$ were male. The mean age was calculated as $60.16 \pm 11.27$ years, and $52 \%$ of the patients had hypertension. There was no difference between the groups in terms of demographic and clinical values. In a compari-

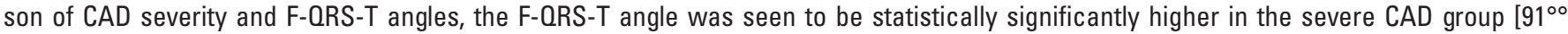
(102/79)] compared to the group with mild $\operatorname{CAD}\left[53^{\circ \circ}(64 / 38)\right]$. In the multivariate logistic regression analysis, there was a significant association between the F-QRS-T angle (odds ratio $=1.09,95 \%$ confidence interval $=1.06-1.11, p<0.001$ ) and CAD severity.

Conclusion: It seems that CAD severity in patients who were non-diabetic and had stable angina pectoris is associated with the F-QRS-T angle.

Keywords: coronary artery disease, stable angina pectoris, frontal QRS-T angle, Gensini score, non-diabetic

Cite this article as: Akın H, Bilge Ö. Relationship between frontal QRS-T duration and the severity of coronary artery disease in who were non-diabetic and had stable angina pectoris. Anatol J Cardiol 2021; 25: 572-8.

\section{Introduction}

Coronary artery diseases (CADs) are among the most important causes of morbidity and mortality worldwide. Coronary angiography (CAG) is used for the diagnosis and treatment of coronary atherosclerotic diseases (1). Chest pain is seen as a problem in CAD. In patients with stable chest pain characterized by typical symptoms related to the character, location, and effort, the basis of the diagnosis is the patient's clinical history, and in most of these cases, it allows for a reliable diagnosis of angina (2). Patients with diabetes mellitus with acute myocardial infarction (MI) and coronary revascularization have been shown to have a worse prognosis than that seen in patients without diabetes mellitus (3). Although the clinical results of changing the perception of pain in patients with diabetes and CAD remain uncertain, some studies have reported that it is more common in patients with diabetes and atypical acute MI, but no significant relationship has been determined between those with diabetes and those without $(4,5)$. Studies on stable CAD have shown that the prevalence of atypical ischemia is more consistent among patients with and without diabetes, but there is not enough information on whether there is such a consistent prevalence among patients with atypical angina (6). The misinterpretation of atypical chest pain may result in negative prognostic results for

Address for Correspondence: Dr. Halil Akın, Sinop Atatürk Devlet Hastanesi,

Kardiyoloji Kliniği, Sinop-Turkey

Phone: +90 5054939007 E-mail: halilakin@yandex.com

Accepted Date: 16.03.2021 Available Online Date: 16.07.2021

(C) Copyright 2021 by Turkish Society of Cardiology - Available online at www.anatoljcardiol.com DOI:10.5152/AnatolJCardiol.2021.33232 


\section{HIGHLIGHTS}

- The frontal-QRS-T (F-QRS-T) angle; is the absolute value of the difference between the ventricular depolarization and repolarization.

- F-QRS-T angle can be measured automatically in the electrocardiogram as well as simply manually.

- The F-ORS-T angle width is associated with severe coronary artery disease.

angina or may affect the physician's diagnostic strategy by not showing evidence of the typicality of symptoms in patients Who were non-diabetic and had stable angina pectoris in CAD (7).

F-ORS-T angle is expressed as the absolute value of the difference between ventricular depolarization and repolarization and as a marker of myocardial depolarization and repolarization heterogeneity (8). QRS-T abnormalities reflect the electrical imbalance of the ventricular myocardium and affect negative cardiovascular outcomes and overall mortality rates, especially in patients with CAD (9). As the relationship between the ORS-T angle changes and CAD has not been studied in patients who were non-diabetic and had stable angina pectoris in the literature, this study aimed to investigate whether there is a relationship between CAD severity and F-ORS-T angle in these patient groups.

\section{Methods}

\section{Study population}

The study was designed as a retrospective cohort study. A total of 202 patients were included in the study after the implementation of the exclusion criteria among 894 patients who got admitted to the outpatient clinic with stable angina pectoris between September 2018 and September 2019. Patients With diabetes, those with a previous history of CAD, those who underwent a coronary artery bypass operation, those with an ischemic change in their ECGs, those with complete and incomplete right or left bundle branch block or pathological 0 , those with a history of cerebral infarction, those with heart failure and arrhythmia (atrial fibrillation or atrioventricular block), those with cardiomyopathies, and those with valvular heart disease were excluded from the study. The patients were given a stress test, and patients with $>1 \mathrm{~mm}$ ST depression in the lateral leads were considered positive. Effort test was positive in all patients included in the study. The F-ORS-T angle calculated on the 12-lead ECGs of the patients (taken in the outpatient clinic) and the CAD severity calculated using the Gensini score (Fig. 1) in patients undergoing CAG were compared. The Gensini score was used to measure the prevalence of CAD in CAG. According to Gensini scores; patients with Gensini score $<25$ points were accepted as the mild CAD group, whereas patients with Gensini score $\geq 25$ points were accepted as the severe CAD group (10). The patients were compared in terms of QRS-T angle, and an evalua-

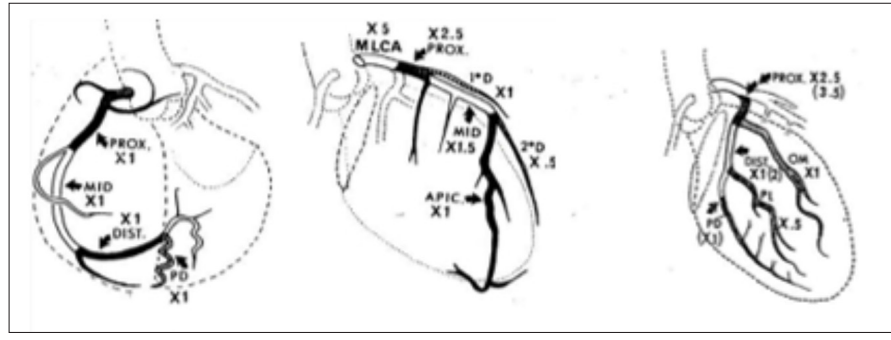

Figure 1. An example demonstrating the measurement of the Gensini score calculation

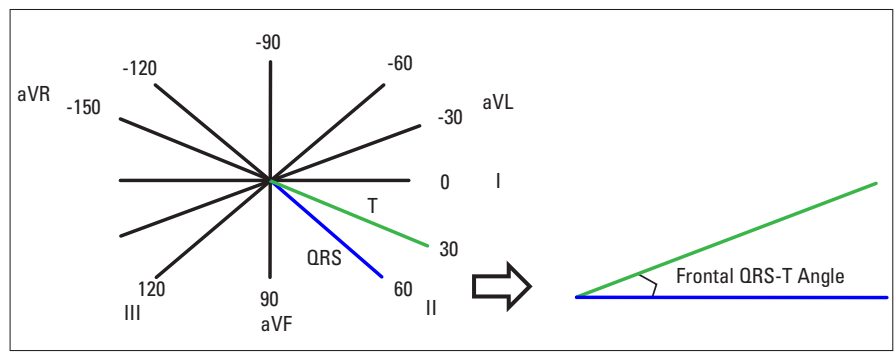

Figure 2. An example demonstrating the measurement of the frontal QRS-T angle

tion was conducted to know whether QRS-T angle indicated the prevalence of CAD. The informed consent of the subjects was obtained, and the study protocol was approved by the Human Research Committee of the Institute. The study protocol conforms to the Declaration of Helsinki (Approval number/date: 578 . 25/09/2020).

\section{Electrocardiography}

A 12-lead ECG was recorded at a paper speed of $25 \mathrm{~mm} / \mathrm{s}$ and voltage of $10 \mathrm{~mm} / \mathrm{mV}$ amplitude in the same device (Cardio Soft version 6.0, GE Medical Systems, Milwaukee, USA). The FrontalQRS and T-wave axes were analyzed automatically (Marquette 12SL software GE Medical Systems, Milwaukee, USA). All ECGs were also checked by a single independent observer. Manual measurement, in short, the QRS deflections, were measured by a ruler in each of the 3 standard leads. The results were then inserted in Einthoven's triangle, and the angle was measured by a protractor. T-waves were measured similarly, and the difference between the ORS- and the T-wave angle was calculated (11). When there was a conflict of $>15^{\circ}$ between automatic and observer measurements, the observer's measurement applied. The F-QRS-T angle was defined as the absolute value of the difference between the QRS and T-wave axes (Fig. 2 and 3). If the F-ORS-T angle was $>180^{\circ}$, the relevant value was determined as follows: $360^{\circ}$ - (QRS axis - T axis). According to the $95^{\text {th }}$ percentile values of a population based study, the F-QRS-T angle was classified as abnormal if it was $\geq 73^{\circ}$ for males and $\geq 67^{\circ}$ for females (12). The frontal T-wave axis was considered abnormal when it was $>75^{\circ}$ or $<15^{\circ}(13)$.

\section{Coronary angiography}

Coronary angiograms were recorded digitally for quantitative analysis (DICOM viewer, MedCom GmbH, Darmstadt, Germany). 


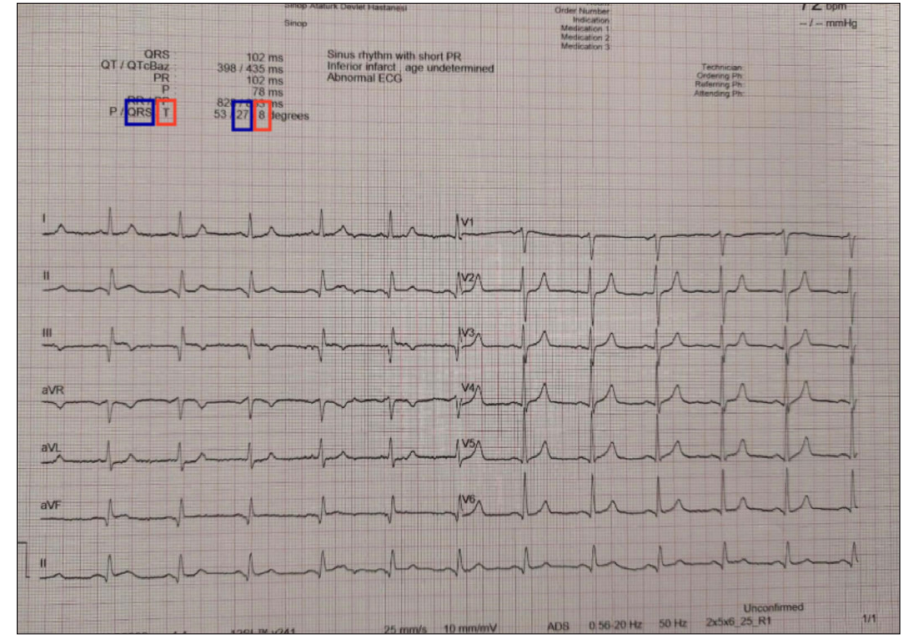

Figure 3. An electrocardiogram example demonstrating the measurement of the frontal QRS-T angle. The QRS axis and T axis were calculated automatically (arrowheads). Then, the frontal QRS-T angle was calculated as the absolute value of the difference between the frontal plane QRS and T axes (frontal QRS-T angle=QRS axis - T axis). For the ECG of the patient demonstrating aforementioned measurement, frontal QRS-T angle $=21^{\circ}\left(\mathrm{QRS}\right.$ axis $=27^{\circ}, \mathrm{T}$ axis $\left.=8^{\circ}\right)$

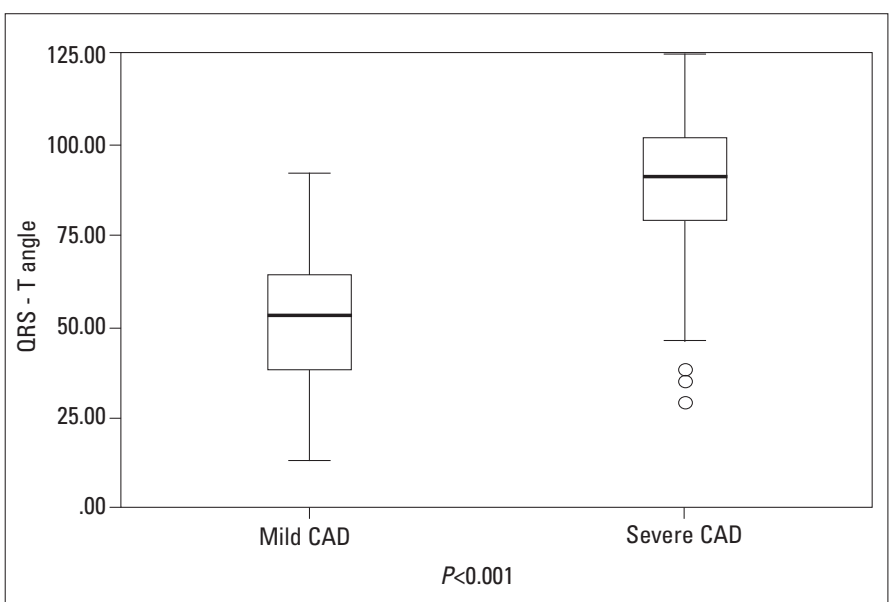

Figure 4. Operating characteristics showing the distinctive utility of frontal QRS-T angles

These digital angiograms were evaluated by 2 experienced cardiologists blinded to other patient information. In case of any contradiction regarding the evaluations, a consensus was reached by discussing the issue. Gensini scores were obtained by multiplying the myocardial area fed by the vascular area with $1,2,4,8,16$, and 32 stenoses, respectively, by the coefficient determined according to functional importance. Accordingly, The left main coronary artery was multiplied by 5 , the proximal left descending artery by 2.5 , the proximal circumflex artery by 2.5 , the left anterior descending artery middle segment by 1.5 , the right coronary artery, the distal left anterior descending artery, and the posterolateral artery and obtuse marginal artery by 1 , and others by 0.5 (Fig. 1) (14). Patients with CAD were divided into the following 2 groups: those below the cut-off value and those above the cut-off value. The first group was composed of those with mild atherosclerosis [Gensini score $<25$ points (mild CAD group)], whereas the second group was composed of those with severe atherosclerosis [Gensini score $\geq 25$ points (severe CAD group)], with this classification compatible with the literature (10).

\section{Statistical methods}

The SPSS 25.0 (IBM Corporation, Armonk, New York, United States) program was used in the analysis of the variables. The conformity of the data to normal distribution was evaluated by the Shapiro-Wilk Francia test. The independent samples $t$-test was used with the Bootstrap results to compare 2 independent groups according to the quantitative data, whereas the Mann-Whitney $\mathrm{U}$ test was used with the Monte Carlo results. The Pearson chisquare test was used with the Exact results to compare categori$\mathrm{cal}$ variables with each other. The logistic regression test was used with the Enter method to determine the cause-effect relationship between the 2 category response variables and explanatory variables. The quantitative variables were shown as mean (standard deviation) and median [quartile (0)1 / 03], while the categorical variables were shown as $n(\%)$ in the tables. The variables were examined at a $95 \%$ confidence interval $(\mathrm{Cl})$, and the $\mathrm{p}$-value was considered significant when it was less than 0.05 .

\section{Results}

Of the 894 patients who applied to the outpatient clinic with stable angina pectoris between September 2018 and September 2019, a total of 202 patients were included in the study after the implementation of the exclusion criteria. The ORS-T angle recorded by the 12-lead ECGs of the patients were compared with their CAD severities. The demographic and clinical variables of the patients included in the study are shown in Table 1. Of all the patients, $38.6 \%$ were female and, $61.4 \%$ were male, and their mean age was calculated as $60.16 \pm 11.27,52 \%$ of the patients had hypertension (HT). According to the CAG results, $48 \%$ of the patients had mild CAD (Gensini score $<25$ ) and $52 \%$ had severe CAD (Gensini score $\geq 25$ ). The mean QRS duration of all patients included in the study were measured as $79.12 \pm 3.90$ seconds the mean QRS-T angle as $71.18 \pm 26.39^{\circ}$, and the mean OTC as $429.52 \pm 16.65$. No significant relationship could be determined between the patients' ages, patients, gender, presence of HT in the patients, patients lipid profiles, patients whole blood parameters, patients kidney function tests, patients pulse, patients QRS durations, and patients OTc data ( $p>0.05$ ) (Tables 1 and 2).

While comparing the CAG data and the F-QRS-T angles of the patient groups, the F-QRS-T angle was found to be average $91^{\circ 0}$ (between 79 and 102) in the severe CAD group, 53०0 (between 38 and 64 ) for the mild CAD group; there was a significant relationship between the 2 groups $(p<0.001)$ (Fig. 4). In the multivariate logistic regression analysis to determine the association of the F-ORS-T angle with CAD severity in patients with stable angina pectoris, a significant association was found between the $\mathrm{F}$ QRS- $T$ angle [odds ratio (OR) $=1.09,95 \% \mathrm{Cl}=1.06-1.11, \mathrm{p}<0.001$ ] and CAD severity (Table 3 ). In addition, the total cholesterol level 


\begin{tabular}{|c|c|c|c|c|}
\hline & Total $(\mathrm{n}=202)$ & Mild CAD (n=97) & Severe CAD ( $n=105$ ) & \\
\hline Variables & Median (01/03) & Median (01/03) & Median (01/03) & $P$-value \\
\hline Age (years) & $58(51 / 69)$ & $58(69 / 51)$ & $59(71 / 52)$ & $0.345^{\mathrm{u}}$ \\
\hline \multicolumn{5}{|l|}{ Gender, $\mathbf{n}(\%)$} \\
\hline Female & $78(38.6)$ & $41(42.3)$ & $37(35.2)$ & \multirow[t]{2}{*}{$0.315^{p}$} \\
\hline Male & $124(61.4)$ & $56(57.7)$ & $68(64.8)$ & \\
\hline \multicolumn{5}{|l|}{ HT, n (\%) } \\
\hline Absent & $97(48.0)$ & $46(47.4)$ & $51(48.6)$ & \multirow[t]{2}{*}{$0.889 \mathrm{p}$} \\
\hline Present & $105(52.0)$ & $51(52.6)$ & $54(51.4)$ & \\
\hline LDL cholesterol (mg/dL) & $132.57(37.67)$ & $132.28(34.41)$ & $132.85(40.62)$ & $0.912^{t}$ \\
\hline HDL cholesterol (mg/dL) & $46.56(38 / 65.4)$ & $49(41.64 / 65.8)$ & $45.2(37.37 / 65.3)$ & $0.317^{\mathrm{u}}$ \\
\hline Triglyceride (mg/dL) & $162.65(130.7 / 208.92)$ & $159(126 / 208.92)$ & $163(135 / 208.92)$ & $0.554^{4}$ \\
\hline Total cholesterol (mg/dL) & $189.6(172.82 / 220)$ & $195(178.9 / 230)$ & $186(169 / 207.9)$ & $0.068^{\mathrm{u}}$ \\
\hline Hemoglobin (g/dL) & $13(12 / 14.5)$ & $13.3(12 / 14.7)$ & $13(11.8 / 14.4)$ & $0.157^{\mathrm{u}}$ \\
\hline Hematocrit \% & $41(38.4 / 44.2)$ & $41.2(38.7 / 44.3)$ & $40.33(37.2 / 44)$ & $0.164^{4}$ \\
\hline Red blood cell (M/uL), mean (SD) & $5.06(0.78)$ & $5.17(0.73)$ & $4.96(0.82)$ & $0.046^{t}$ \\
\hline White blood cell count $\left(10^{3} / \mathrm{mL}\right)$ & $8.45(6.8 / 9.75)$ & $7.99(6.8 / 9.76)$ & $8.47(6.8 / 9.74)$ & $0.872^{\mathrm{u}}$ \\
\hline Red cell distribution width (\%) & $14(13.2 / 14.7)$ & $14(13 / 14.6)$ & $13.9(13.3 / 14.7)$ & $0.343^{\mathrm{u}}$ \\
\hline Mean platelet volume (fL) & $11.2(10.3 / 11.65)$ & $11(10 / 11.6)$ & $11.3(10.5 / 11.65)$ & $0.158^{\mathrm{u}}$ \\
\hline Uric acid (mmol/L) & $6(5 / 7)$ & $6(5 / 6)$ & $6(5 / 7)$ & $0.057^{\mathrm{u}}$ \\
\hline e-GFR (mL/min) & $55(46 / 60)$ & $55(48 / 60)$ & $55(46 / 60)$ & $0.366^{\mathrm{u}}$ \\
\hline Urea (mg/dL) & $33.46(27.65 / 41.1)$ & $33.46(27.45 / 40.75)$ & $33.46(28.13 / 41.7)$ & $0.459^{\mathrm{u}}$ \\
\hline Creatinine (mmol/L) & $0.905(0.69 / 1.2)$ & $0.95(0.71 / 1.19)$ & $0.9(0.69 / 1.2)$ & $0.929^{\mathrm{u}}$ \\
\hline Ejection fraction $(\%)$ & $47(42 / 55)$ & $49(44 / 55)$ & $45(42 / 55)$ & $0.373^{\mathrm{u}}$ \\
\hline Heard rate (beat/min) & $78.82(4.93)$ & $78.99(4.68)$ & $78.66(5.17)$ & $0.609 \mathrm{t}$ \\
\hline QRS-T angle & $73(50 / 92)$ & $53(38 / 64)$ & $91(79 / 102)$ & $<0.001^{\mathrm{u}}$ \\
\hline QRS duration (ms) & $79(76 / 82)$ & $79(76 / 81)$ & $79(76 / 82)$ & $0.617^{u}$ \\
\hline QTc (ms) & $427(420 / 438)$ & $428(419 / 438)$ & $427(421 / 437)$ & $0.928^{\mathrm{u}}$ \\
\hline
\end{tabular}

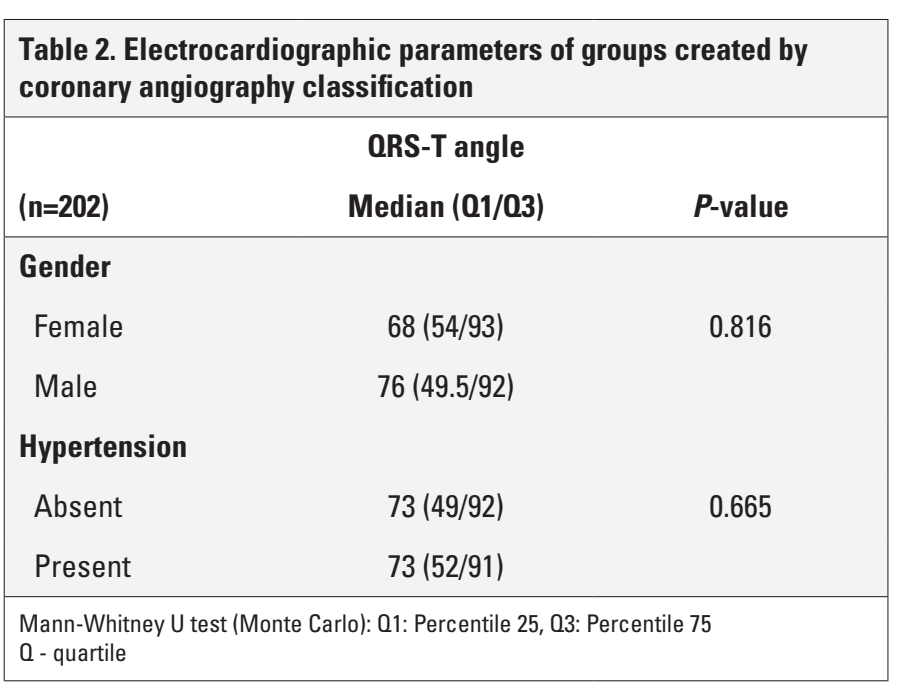

was found to be significantly higher in the severe $C A D$ group (OR=1.01, 95\% $\mathrm{Cl}=1.00-1.02, \mathrm{p}=0.031$ ).

\section{Discussion}

To the best of our knowledge, this study is the first study in the literature to investigate F-ORS-T angle and the severity of CAD in patients who were non-diabetic and had SAP. In the study, a significant relationship was found between the F-ORS-T angle and the intensity of CAD severity. Of the patient population included in the study, $38.6 \%$ were female and, $61.4 \%$ were male, and their mean age was calculated as $60.16 \pm 11.27 ; 52 \%$ of the patients had HT. In addition, no significant correlation was found between the study groups in terms of the demographic characteristics and biochemical parameters of the patients included in the study. 


\begin{tabular}{|c|c|c|c|c|c|c|}
\hline \multirow[b]{2}{*}{ Reference group: Severe CAD } & \multirow[b]{2}{*}{ B } & \multirow[b]{2}{*}{ SE } & \multirow[b]{2}{*}{$P$-value } & \multirow[b]{2}{*}{ OR } & \multicolumn{2}{|c|}{ 95\% Cl for OR } \\
\hline & & & & & Lower bound & Upper bound \\
\hline Gender & 0.037 & 0.445 & 0.402 & 0.688 & 0.288 & 1.647 \\
\hline HT & 0.369 & 0.454 & 0.417 & 1.446 & 0.593 & 3.524 \\
\hline Triglyceride & 0.002 & 0.002 & 0.481 & 1.002 & 0.997 & 1.006 \\
\hline Total cholesterol $(\uparrow)$ & 0.013 & 0.006 & 0.031 & 1.013 & 1.001 & 1.025 \\
\hline Red blood cell, M/uL & -0.246 & 0.272 & 0.365 & 0.782 & 0.458 & 1.333 \\
\hline QRS-T angle $(\uparrow)$ & 0.087 & 0.011 & $<0.001$ & 1.091 & 1.067 & 1.115 \\
\hline
\end{tabular}

CAD is a leading cause of morbidity and mortality in patients with diabetes. Diabetes is known to be associated with the development of $C A D$, and the prognosis of the disease worsens owing to diabetes (15). According to the information obtained in a study conducted with multivariate-adjusted risk models, it is noted that the spatial QRS-T angle is a significant and strong predictor of CAD in females compared with in males, with a hazard ratio of 2.14 (11).

In this study, the comparison of the F-QRS-T angle and the CAG data of patients with stable angina pectoris was conducted. According to the literature, as CAD is common in patients with diabetes, this study compared CAG data and F-QRS-T angle of patients who were non-diabetic and stable angina pectoris. It was seen that there was almost no previous study on this subject, and it was thought that this gap in the literature could be addressed by this study.

QRS-T angle is defined as the angle between the depolarization and repolarization electrical directions and as a new marker of myocardial depolarization and repolarization heterogeneity (12). Studies have shown that the QRS-T angle is both more robust and reproducible and less sensitive to noise and definition problems when compared with other conventional electrocardiographic myocardial repolarization parameters (16). The QRS-T angle is determined by the 3 dimensional spatial QRS-T angle method and the frontal QRS-T angle calculation method using a projection on the frontal plane in the standard 12-lead ECG (8). As most ECG devices automatically report the QRS and $\mathrm{T}$-axes, the F-ORS-T angle can be easily calculated from the surface ECG by subtracting the ORS-axis from the T-axis (17). F-QRS-T angle abnormalities reflect electrical instability and the heterogeneity of myocardial repolarization. The F-ORS-T angle is effective in detecting repolarization abnormalities before significant ECG changes occur (18). Normally, the result of balanced regulation of electrical activity and recovery; and the ventricular depolarization and repolarization axis are in the same direction, and it results in a sharp QRS axis change (19). Chronically, ischemic myocardium causes delayed conduction in the local Purkinje fibers and partial depolarization and repolarization of the ventricle (20). It results in slow activation of the myocardium. This slow activation is one of the most important reasons for the instability of depolarization and repolarization homogeneity (21). In conclusion, damaged or inhomogeneous areas of the myocardium owing to ischemia results in abnormal ventricular repolarization, and a widening F-ORS-T angle appears. In a study, it was reported that the F-QRS-T angle was an appropriate clinical substitute for the spatial QRS-T angle in risk estimation. With a correction for demographic and clinical features, the F-ORS-T angle wideness was a strong predictor of total mortality with a $>50 \%$ increased risk and was a strong predictor of incident CAD with a $74 \%$ increased risk (11). On the basis of the CAG results of all patients included in this study, a medical treatment was decided for $31.2 \%$, coronary slow flow for $16.8 \%$, percutaneous coronary intervention for $37.1 \%$, and coronary bypass for $14.9 \%$ of the patients. When CAD severity was calculated with the Gensini score, mild and severe CAD were detected in $48 \%$ and $53 \%$ of patients, respectively. The mean ORS duration of all patients included in the study was measured as $79.12 \pm 3.90$ seconds, the QRS-T angle as $71.18 \pm 26.39^{\circ \circ}$, and the $\mathrm{OTC}$ as $429.52 \pm 16.65$. Considering the study groups created, no significant relationship could be found between the groups according to the pulse, ORS durations, and QTC data of all patients.

In some studies, the relationship between F-ORS-T angle and the severity of CAD was investigated, and it was found that the prevalence of CAD with 2 or 3 vascular occlusions was significantly higher in patients with a planar QRS-T angle $>90^{\circ}$ Than in patients with a planar QRS-T angle $\leq 90^{\circ}$ (22). In a study conducted on patients with 3 vascular occlusions, a statistical- 
ly significant difference was found between the number of patients with a F-QRS-T angle $\geq 95.6^{\circ}$ and the number of patients with a F-QRS-T $\leq 95.6^{\circ}$. They thought that the possible cause of this may be related to an increase in the F-QRS-T angle of the lesion accompanying CAD not associated with infarction and found that patients with a F-ORS-T angle $\geq 95.6^{\circ}$ more frequently had proximal vascular disease (23). In a recent study, damaged or inhomogeneous areas of ischemia-induced myocardium resulted in abnormal ventricular repolarization and revealed a widening QRS-T angle. In the same study, it was shown that hemodynamically significant occlusion in the epicardial coronary artery resulted in a wider QRS-T angle associated with ischemia and a significant narrowing in the QRS-T angle after revascularization (24). In another study, it was found that QRS and T-axes changes were associated with transient ischemic attacks in patients with coronary artery occlusion (25). They also revealed that the association of a wide QRS-T angle with a 6 -year mortality risk in patients with ischemic chest pain was 1.5 times greater (26). In this study, however, when the severe CAD group [average $91^{\circ \circ}$ (between 79 and 102)] and the mild CAD group [average $53^{\circ \circ}$ (between 38 and 64)] were compared, it was seen that there was a statistically significant relationship between the F-ORS-T angles. These findings suggest that the F-ORS-T angle may be a useful parameter in demonstrating CAD severity in patients with stable angina pectoris.

\section{Study limitations}

The small sample size of the study was the main limitation. In addition, in some studies, it was demonstrated that spatial QRS$\mathrm{T}$ angle can be more superior to the frontal planar QRS-T angle for cardiac risk protection. The lack of data reated to the spatial QRS-T angle values is the other limitation.

\section{Conclusion}

In the light of these data, it was seen that there was a significant relationship between the changes in F-ORS-T angles and CAD in patients who were non-diabetic and had angina, and if the F-ORS-T angle is greater than $91^{\circ}$, severe CAD should be considered. Besides, before performing an invasive procedure, the method employed in measuring F-ORS-T angles, one of the repolarization markers for detecting CAD severity, was considered to be of broad utility for these patient groups.

Acknowledgements: We would like to thanks Ass. Prof. Bernas Altıntaş for his support for the statistics of our study.

Conflict of interest: None declared.

Peer-review: Externally peer-reviewed.

Author contributions: Concept-H.A.; Design-H.A., Ö.B.; Supervision - H.A., Ö.B.; Fundings - None; Materials - H.A., Ö.B.; Data collection \&/or processing - H.A., Ö.B.; Analysis \&/or interpretation - H.A., Ö.B.; Literature search - H.A., Ö.B.; Writing - H.A.; Critical review - H.A., Ö.B.

\section{References}

1. Neumann FJ, Sousa-Uva M, Ahlsson A, Alfonso F, Banning AP, Benedetto U, et al.; ESC Scientific Document Group. 2018 ESC/ EACTS Guidelines on myocardial revascularization. Eur Heart $\mathrm{J}$ 2019; 40: 87-165. [Crossref]

2. Junghans C, Sekhri N, Zaman MJ, Hemingway H, Feder GS, Timmis A. Atypical chest pain in diabetic patients with suspected stable angina: impact on diagnosis and coronary outcomes. Eur Heart $\mathrm{J}$ Qual Care Clin Outcomes 2015; 1: 37-43. [Crossref]

3. Karayannis G, Giamouzis G, Cokkinos DV, Skoularigis J, Triposkiadis F. Diabetic cardiovascular autonomic neuropathy: clinical implications. Expert Rev Cardiovasc Ther 2012; 10: 747-65. [Crossref]

4. Kwong RY, Sattar H, Wu H, Vorobiof G, Gandla V, Steel K, et al. Incidence and prognostic implication of unrecognized myocardial scar characterized by cardiac magnetic resonance in diabetic patients without clinical evidence of myocardial infarction. Circulation 2008; 118: 1011-20. [Crossref]

5. Omerovic E, Brohall G, Müller M, Råmunddal T, Matejka G, Waagstein $F$, et al. Silent myocardial infarction in women with type II diabetes mellitus and microalbuminuria. Ther Clin Risk Manag 2008; 4: 705-12. [Crossref]

6. Angerud KH, Brulin C, Näslund U, Eliasson M. Patients with diabetes are not more likely to have atypical symptoms when seeking care of a first myocardial infarction. An analysis of 4028 patients in the Northern Sweden MONICA Study. Diabet Med 2012; 29: e82-7. [Crossref]

7. National Institute for Health and Clinical Excellence (NICE). Chest pan of recent onset: assessment and diagnosis of recent onset chest pain or discomfort of suspected cardiac origin. NICE guidelines (CG95) (March 2010). Available from: URL: https://www.nice. org.uk/guidance/cg95/

8. Oehler A, Feldman T, Henrikson CA, Tereshchenko LG. QRS-T angle: a review. Ann Noninvasive Electrocardiol 2014; 19: 534-42. [Crossref]

9. Giannopoulos G, Dilaveris P, Batchvarov V, Synetos A, Hnatkova K, Gatzoulis K, et al. Prognostic significance of inverse spatial QRS-T angle circadian pattern in myocardial infarction survivors. J Electrocardiol 2009; 42: 79-84. [Crossref]

10. Oishi Y, Wakatsuki T, Nishikado A, Oki T, Ito S. Circulating adhesion molecules and severity of coronary atherosclerosis. Coron Artery Dis 2000; 11: 77-81. [Crossref]

11. Zhang ZM, Prineas RJ, Case D, Soliman EZ, Rautaharju PM; ARIC Research Group. Comparison of the prognostic significance of the electrocardiographic QRS/T angles in predicting incident coronary heart disease and total mortality (from the atherosclerosis risk in communities study). Am J Cardiol 2007; 100: 844-9. [Crossref]

12. Zhang ZM, Rautaharju PM, Prineas RJ, Tereshchenko L, Soliman EZ. Electrocardiographic QRS-T angle and the risk of incident silent myocardial infarction in the Atherosclerosis Risk in Communities study. J Electrocardiol 2017; 50: 661-6. [Crossref]

13. Kors JA, de Bruyne MC, Hoes AW, van Herpen G, Hofman A, van Bemmel JH, et al. T-loop morphology as a marker of cardiac events in the elderly. J Electrocardiol 1998; 31 Suppl: 54-9. [Crossref]

14. Gensini GG. A more meaningful scoring system for determining the severity of coronary heart disease. Am J Cardiol 1983; 51: 606. [Crossref]

15. Lima EG, Hueb W, Garcia RM, Pereira AC, Soares PR, Favarato D, et al. Impact of diabetes on 10-year outcomes of patients with multi- 
vessel coronary artery disease in the Medicine, Angioplasty, or Surgery Study II (MASS II) trial. Am Heart J 2013; 166: 250-7. [Crossref]

16. Dilaveris P, Antoniou CK, Gatzoulis K, Tousoulis D. T wave axis deviation and QRS-T angle - Controversial indicators of incident coronary heart events. J Electrocardiol 2017; 50: 466-75. [Crossref]

17. Li YH, Ren XJ, Han ZH, Wang YL, Wang Y, Zhang JR, et al. Value of the frontal planar QRS-T angle on cardiac dysfunction in patients with old myocardial infarction. Int J Clin Exp Med 2013; 6: 688-92.

18. De Bruyne B, Fearon WF, Pijls NH, Barbato E, Tonino P, Piroth Z, et al.; FAME 2 Trial Investigators. Fractional flow reserve-guided PCI for stable coronary artery disease. N Engl J Med 2014; 371: 1208-17. [Crossref]

19. Scherptong RW, Henkens IR, Man SC, Le Cessie S, Vliegen HW, Draisma $\mathrm{HH}$, et al. Normal limits of the spatial QRS-T angle and ventricular gradient in 12-lead electrocardiograms of young adults: dependence on sex and heart rate. J Electrocardiol 2008; 41: 64855. [Crossref]

20. Birnbaum $Y$, Sclarovsky S. The grades of ischemia on the presenting electrocardiogram of patients with ST elevation acute myocardial infarction. J Electrocardiol 2001; 34 Suppl: 17-26. [Crossref]

21. Gardner PI, Ursell PC, Fenoglio JJ Jr, Wit AL. Electrophysiologic and anatomic basis for fractionated electrograms recorded from healed myocardial infarcts. Circulation 1985; 72: 596-611. [Crossref]

22. Palaniswamy C, Singh T, Aronow WS, Ahn C, Kalapatapu K, Weiss $\mathrm{MB}$, et al. A planar QRS-T angle $>90$ degrees is associated with multivessel coronary artery disease in patients undergoing coronary angiography. Med Sci Monit 2009; 15: MS31-4. [Crossref]

23. Colluoglu T, Tanriverdi Z, Unal B, Ozcan EE, Dursun H, Kaya D. The role of baseline and post-procedural frontal plane QRS-T angles for cardiac risk assessment in patients with acute STEMI. Ann Noninvasive Electrocardiol 2018; 23: e12558. [Crossref]

24. Kahraman S, Kalkan AK, Turkyilmaz AB, Dogan AC, Avci Y, Uzun F, et al. Frontal ORS-T angle is related with hemodynamic significance of coronary artery stenosis in patients with single vessel disease. Anatol J Cardiol 2019; 22: 194-201. [Crossref]

25. Shirota K, Ogino K, Hoshio A, Kasahara T, Kotake H, Endo S, et al. Changes of QRS axis in transient myocardial ischaemia induced by percutaneous transluminal coronary angioplasty. Eur Heart J 1994; 15: 1391-5. [Crossref]

26. de Torbal A, Kors JA, van Herpen G, Meij S, Nelwan S, Simoons ML, et al. The electrical T-axis and the spatial QRS-T angle are independent predictors of long-term mortality in patients admitted with acute ischemic chest pain. Cardiology 2004; 101: 199-207. [Crossref] 